\title{
BRINGING UP CHILDREN IN ENGLISH, FRENCH AND IRISH: TWO CASE STUDIES
}

summarised by the

sinners will find a lot

Language Monthly into the field . . . as vithout entirely overbout the first edition efinitions and TypoMorphological Transfer, Code Switching); tical Considerations

1986 MM1 205 pages

TD

don

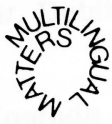

\section{rth to Teens}

dren: Guidance for the ful bilinguals to the age tions to the original text : a family language and went to school in Gerctory chapters cover the modified to include the receive the same sort of ves to be widely known $r$ children bilingually. It ingualism and among all ducational consequences $\mathrm{rt}$ in Language in Society ributions to the field.' Educational Supplement bk 1-85359-009-6£7.95 \$17.00

LTD edon,

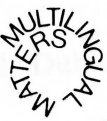

Christine Helot

Language Centre, St Patrick's College, Maynooth, Co. Kildare, Ireland.

Abstract Two case studies of children being brought up trilingually, (English, French and Irish) are presented. Patterns of language use are described and compared for the three languages, with the emphasis on function more than degree of proficiency. It is shown that the use of the minority language (Irish) is dependent on the exclusion of the majority language (English). The paper also looks at the validity of Lambert's (1975) distinction between 'additive' and 'subtractive' bilingualism, and his claim that the 'roots' of bilingualism are in the sociopsychological aspects of language use, especially in the relative status of the two languages, as perceived by the learner.

\section{Introduction}

Although there are many parts of the world in which children acquire three or more languages (Grosjean, 1982), there is little research on the topic, by comparison with the many studies of child bilingualism. Harding \& Riley (1986) present 16 case studies of bilingual families and one among them is a trilingual (French, German, Portuguese) family. The father and mother are French- and German-speaking, respectively, and the family lives in Brazil. Arnberg (1987) describes a trilingual (Finish, Kurdish, Swedish) family where the mother is a Finn, the father a Kurd, and the family lives in Sweden. The parents speak their own languages to the children and Swedish to one another.

Hoffman's study (1985) of language acquisition in two trilingual children (her own) describes how they acquired two languages first (Spanish and German) and later on, while still very young, a third language (English). Each parent uses his or her own language with the children. The mother is a native speaker of German, the father is a native speaker of Spanish. The family lives in the U.K. and Spanish is the medium of communication between them at home. Hoffman's study is more detailed than the case studies mentioned above in that she gives an account of the patterns of acquisition of the three languages, examples of interference and results of vocabulary recall tests which show a certain order of competence with English in first position, followed by German then Spanish. She also mentions a factor which is very important but makes the study of trilingualism all the more difficult: competence in the three languages changes over the years. She concludes by saying that bilingualism is a matter of degree and the aims of parents should be 
realistic. The bilingual child or trilingual child should not be expected to achieve monolingual standard in two or three languages but in at least one language, usually the language of education.

Magiste (1984) asks a different question which however also relates to trilingualism: Is learning a third language easier for bilingual immigrant students than learning a second language for monolingual students? She discusses the results of two studies carried out in Sweden and Germany which show that passive bilingualism seems to facilitate learning a third language, while active bilingualism appears to delay it.

This contradicts an earlier report by Albert \& Obler (1978) which showed that early bilinguals pick up a third language more easily. She explains her results thus: passive knowledge of a language means that the student has acquired the technique of learning another language, which obviously improves the learning of additional languages; active knowledge of a language can give rise to interference since the potential for interference increases with the number of languages a student knows.

\section{The Study}

\section{Subjects, method and data}

The two trilingual families studied live in Dublin and in both cases the mother is French and the father Irish. Both fathers are native speakers of Irish. Each family has two children, two boys of 13.2 and 8.7 in the first and a boy of 9.0 and a girl of 7.0 in the second.

The families were interviewed in detail in order to determine who spoke what language to whom, when, where and why. A summary of the results is presented in Table 1.

In Family 1 the first boy heard only French from both his parents until he was three, and English, which is the community language, as soon as he started going to an English playgroup. Irish has been acquired in a regular (English-medium) primary school, where it is taught as a school subject for one period per day, and also through regular visits to the Gaeltacht. The second child heard French from his mother and English from his father, and is also learning Irish in an English-medium primary school.

The two children in Family 2 were in contact with two languages from birth, French from their mother, and Irish from their father for whom it is the first language. The children were in contact with English from the time they could play in the street, around three years of age. They attended Irish-medium primary school from the age of four.

\section{Results}

Language use in Family 1 is presented in three different contexts: Dublin, where the family lives most of the time, France, where the family goes at least 
be expected to achieve at least one language,

vever also relates to al immigrant students ts? She discusses the any which show that language, while active

78) which showed that plains her results thus: lent has acquired the nproves the learning of give rise to interference umber of languages a

both cases the mother peakers of Irish. Each st and a boy of 9.0 and

rmine who spoke what the results is presented

his parents until he was soon as he started going gular (English-medium) one period per day, and hild heard French from $o$ learning Irish in an

o languages from birth, for whom it is the first the time they could play I Irish-medium primary

ferent contexts: Dublin, the family goes at least
Table 1 Use of Irish, French and English in the families studied

\begin{tabular}{|c|c|c|c|c|c|c|c|c|c|}
\hline & \multicolumn{3}{|c|}{ In Dublin } & \multicolumn{3}{|c|}{ In France } & \multicolumn{3}{|c|}{ In the Gaeltacht } \\
\hline & Ir & $F r$ & Eng & $I r$ & $F r$ & Eng & Ir & $F r$ & Eng \\
\hline \multicolumn{10}{|l|}{ Family 1} \\
\hline Father to Mother & & & $* * *$ & & & $* * *$ & & $* * *$ & \\
\hline Mother to father & & $* *$ & $* * *$ & & $* * *$ & & & $* * *$ & \\
\hline Father to children & $*$ & & $* * *$ & & & $* * *$ & $* * *$ & $*$ & \\
\hline Mother to children & & $* * *$ & & & $* * *$ & & & $* * *$ & \\
\hline Children to mother & $*$ & & $* * *$ & & $* * *$ & & & $* * *$ & \\
\hline Children to father & & & $* * *$ & & & $* * *$ & $* * *$ & & \\
\hline Children to children & & & $* * *$ & & $* * *$ & $* * *$ & $* * *$ & $* * *$ & \\
\hline Mealtime & $*$ & $* * *$ & $* * *$ & & $* * *$ & & $* * *$ & $* * *$ & \\
\hline Reading books & $*$ & $* * *$ & $* * *$ & & $* * *$ & & $* * *$ & $* * *$ & \\
\hline Language at school & $*$ & & $* * *$ & & & & $* * *$ & & \\
\hline Lang. outside home & & & $* * *$ & & $* * *$ & $*$ & $* * *$ & $* *$ & \\
\hline \multicolumn{10}{|l|}{ Family 2} \\
\hline Father to mother & & $* * *$ & & & $* * *$ & & & $* * *$ & \\
\hline Mother to father & & $* * *$ & & & $* * *$ & & & $* * *$ & \\
\hline Father to children & * & $* *$ & & * & $* *$ & & * & $* *$ & \\
\hline Mother to children & * & $* * *$ & & $*$ & $* * *$ & & $*$ & $* * *$ & \\
\hline Children to father & $* *$ & $* * *$ & & $* *$ & $* * *$ & & $* *$ & $* * *$ & \\
\hline Children to mother & & $* * *$ & & & $* * *$ & & & $* * *$ & \\
\hline Children to children & $*$ & $* *$ & $*$ & $*$ & $* *$ & $*$ & $*$ & $* *$ & $*$ \\
\hline Mealtime & & $* * *$ & & & $* * *$ & & & $* * *$ & \\
\hline Reading books & $*$ & $* * *$ & $* *$ & $*$ & $* * *$ & $* *$ & $*$ & $* * *$ & $* *$ \\
\hline Language at school & $* * *$ & & $*$ & $* * *$ & & $*$ & $* * *$ & & * \\
\hline Language outside home & $*$ & & $* * *$ & $*$ & & $* * *$ & $*$ & & $* * *$ \\
\hline
\end{tabular}

Key Language: Ir, Irish; Fr, French; Eng, English. Degree of use: ***, mostly; **, some; *, a little.

once a year, for a month or two, and the Gaeltacht, where the whole family has been going for the past two years for two months in the summer.

As the table shows, English is the dominant language of the family in Dublin, though the mother always addresses her children in French (occasionally in English, when she is angry), and they answer her mostly in English (occasionally in French, when they want a favour). In France, however, the family stays with grandparents who do not know any English. French becomes the dominant language, though the father continues to speak English to his children, because when he uses French his children comment on his mistakes. The youngest boy, who does not speak much French in Dublin, uses it very successfully when he is in France.

In the Gaeltacht yet another pattern of language use arises. The father teaches in one of the Irish summer schools where the basic rule is that no one is allowed to speak English. Thus English is excluded from family life. The children speak Irish 
to their father, and French to their mother. Interestingly, the children also use French to communicate between themselves.

Language use in Family 2 is less complex and can be described in a single context. Apart from this, Family 2 differs from Family 1 in one main aspect: the exclusion of English from the home. Because no English is used in the home since the birth of the children, Irish occupies an important place in the life of the family. In addition, the children attend an Irish-medium school and mix a lot with other children being educated through Irish. Another important factor relating to the exclusion of English is the fact that the family does not possess a television set. This factor is mentioned by Chester (1977) who sees the absence of television or, at any rate, restricted viewing of programmes in the majority language as one of the conditions for effective minority language development. The other condition is that a person of the child's household uses the minority language throughout the period when the child is first learning to speak, read and write.

On the subject of literacy, parents in both families thought it important that books in the three languages were available, to be read by the parents to the children, and, later, to be read by the children themselves. In Family 2 the children were taught to read in French by their mother before they went to primary school. In Family 1 the eldest child transferred his reading ability in English to French on his own around the age of eight or nine.

The pattern of language use in these two families reflects the degree of linguistic competence of the children involved, as assessed by their parents. The children of Family 1 are considered by their parents to be native speakers of English, competent speakers of French (but not equal to native speakers of French in France), and to have a 'working knowledge' of Irish (in the case of the eldest child). The children of Family 2 are considered by their parents to be native speakers of all three languages, though it is felt their French is not quite the same as the French of monolingual peers in France, and their Irish, unlike their French, reflects a restricted experience of the language, as they do not have access to television, magazines and a wide variety of speakers of all ages, as they do in the case of French when they visit France.

Language mixing is reported to occur in certain definite situations. In Family 1 the parents noticed language mixing (English words in French speech) when the French grandparents are visiting the family in Dublin (but not when in France), and on return to Ireland after a month or two in France. In Family 2 language mixing (Irish words in French speech) occurs only occasionally, for example, when the children are talking in French about what they have done in Irish in school.

The parents were also asked about the degree of trilingualism which they felt it was possible to achieve in the home. Family 1 felt that there was a difficulty with Irish since it has no support in the environment outside the home, hence their reliance on the Gaeltacht, with its strict exclusion of English, to prevent English from taking over. Family 2 felt raising children trilingually does not demand any particular effort once the choice has been made, based on valid motives, such as the desire to pass on one's own language to one's children. 
ildren also use

bed in a single nain aspect: the the home since the life of the d mix a lot with actor relating to sess a television nce of television language as one ent. The other nority language read and write. important that e parents to the in Family 2 the re they went to eading ability in

gree of linguistic . The children of kers of English, ers of French in ase of the eldest nts to be native ot quite the same like their French, t have access to as they do in the

ions. In Family 1 speech) when the when in France), amily 2 language illy, for example, done in Irish in

which they felt it is a difficulty with ome, hence their o prevent English s not demand any d motives, such as

\section{Discussion}

The most striking feature of the data is the manner in which they reflect the linguistic realities in which the families live, i.e. the position of the three languages in their daily lives, and the choices made by the parents in adapting to these realities.

While Irish and English are the two national official languages of Ireland, a bilingual country, English is the majority language and Irish is used on a regular and frequent basis by less than $10 \%$ of the population, although it is highly valued by the population in general for reasons of cultural identity (Ó Riagáin \& Ó Gliasáin, 1984).

The French language in Ireland enjoys a high status and is studied by over $80 \%$ of entrants to post-primary school (less than 10\% take German, the next most popular foreign language). In addition attitudes to French in the adult population are positive (Little, Singleton \& Silvius, 1984). French is also considered to be a more 'useful' language than Irish (Ó Riagáin \& Ó Gliasáin, 1984).

The two case studies presented above show that French and English are not in competition with one another, reflecting the positive attitudes towards French shared by the largely English-speaking population. At the same time French, being a 'foreign' language, does not represent a threat to the Irish language, although it occupies a larger place than Irish in the families studied here, since the linguistic context, for them, was much richer in French.

In this connection it is useful to consider Lambert's (1975) distinction between additive and subtractive bilingualism. In the first case a second language is added to the first and the languages and their associated cultures complement and enrich each other. In the second case the second language is acquired at the expense of the aptitudes already acquired in the first language, and there is competition between the two linguistic and cultural systems.

Hamers \& Blanc (1983) point out that additive and subtractive bilingualism are hypothetical concepts only, and that research is needed to validate the distinction and to identify the factors leading to one form of bilingualism rather than the other. The present study suggests that the perceived status of the languages involved is the critical factor.

The subjects in this study are living in a country where English is the everyday language, where Irish a minority or lesser-used language spoken mostly in restricted rural areas, and where French is a prestigious foreign language taught in most schools but rarely if ever heard outside them. By speaking French to their children the parents are adding a new language to their children's repertory of skills and exposing them to another culture which is highly valued in Ireland. At the same time they are not posing any threat to the position of English. In the case of Irish it cannot be denied that English is, pragmatically and economically at least, a more prestigious language, while the everyday use of Irish, even passively, on radio and television, for example, is severely limited. Thus English-French bilingualism occurs in an 'additive' context. On the other hand, the relationship between Irish and English, because of historical factors and social constraints 
pertaining in Ireland today, creates what Lambert refers to as a 'subtractive' context. The Irish language is under threat from the English language and the acquisition of English will often gradually take the place of Irish.

To compensate for this subtractive relationship, the exclusion of English is an essential strategy for the transmission of Irish. In our study, English was excluded almost totally from family life in one case, and during visits to the Gaeltacht in the other. In both cases the parents also wanted their children to be educated through Irish, thus excluding English as much as possible from the school as well as the home environment. When practical problems made this impossible for Family 1, the summer courses in the Gaeltacht were chosen as an alternative.

It is in this context that the rapid growth of Irish-medium schools in Ireland in recent years is to be explained. These schools play a role of prime importance for families who want to pass on the Irish language to their children. Learning Irish as a second language in English-medium primary and secondary school has proved extremely difficult, and has often encouraged negative attitudes towards Irish.

These remarks are not meant to criticise school methods for teaching languages. In fact it is difficult to say how methods of teaching languages as single subjects in school should be modified in the light of pleasant experiences of children learning languages in other contexts. The least that may be said, however, is that bilingual children are often astonished at the way languages are taught in school. More generally, as Hamers \& Blanc (1983) point, out it is important that the languages to which children are exposed, whether in school or outside of it, be highly valued socially and culturally. If this is the case, then children will interiorise all the positive values associated with the languages, and will create for themselves positive personal values for each language, and thus for language in general.

\section{References}

Albert, M. L. and Obler, L. K. (1978) The Bilingual Brain. New York: Academic Press. Arnberg, L. (1987) Raising Children Bilingually: The Pre-School Years. Clevedon, U.K.: Multilingual Matters.

Chester, C., Christian Jr (1977) Minority language skills before age 3. In W. F. Mackey and T. Andersson, (eds), Bilingualism in Early Childhood. Rowley. MA.: Newbury House.

Grosjean, F. (1982) Life with Two Languages. An Introduction to Bilingualism. Cambridge, MA.: Harvard University Press.

Hamers, J. F. and Blanc, M. (1983) Bilinguisme et Bilingualité. Bruxelles: Mardaga.

Harding, E. and Riley, P. (1986) The Bilingual Family. Cambridge: Cambridge University Press.

Hoffman, C. (1985) Language acquisition in two trilingual children. Journal of Multilingual and Multicultural Development 6, 479-96.

Lambert, W. E. (1975) Culture and language as factors in learning and education. In A. Wolfgang, (ed.), Education of Immigrant Students. Toronto: Ontario Institute for Studies in Education. 
to as a 'subtractive' ish language and the f Irish.

1sion of English is an English was excluded ts to the Gaeltacht in ldren to be educated om the school as well e this impossible for $n$ as an alternative. schools in Ireland in prime importance for ldren. Learning Irish econdary school has ive attitudes towards

ethods for teaching ng languages as single asant experiences of that may be said, he way languages are 983) point, out it is whether in school or this is the case, then th the languages, and anguage, and thus for

York: Academic Press. Years. Clevedon, U.K.:

age 3. In W. F. Mackey Rowley. MA.: Newbury ıction to Bilingualism. Bruxelles: Mardaga. : Cambridge University children. Journal of $\mathrm{g}$ and education. In A. Ontario Institute for
Little, D. G., Singleton, D. M. and Silvius, W. M. F. (1984) Learning Second Languages in Ireland: Experience, Attitudes and Needs. Trinity College, Dublin: Centre for Language and Communication Studies.

Magiste, E. (1984) Learning a third language. Journal of Multilingual and Multicultural Development 5, 415-21.

Ó Riagáin, P. and Ó Gliasáin, M. (1984) The Irish Language in the Republic of Ireland 1983: Preliminary Report of a National Survey. Dublin: Linguistics Institute of Ireland.

\section{RAISING CHILDREN BILINGUALLY: The Pre-school Years Lenore ARNBERG}

"This is a book whose time has come. I welcome it and wish it well and will refer to it often in conjunction with my own bilingual grandchildren... I feel indebted to Arnberg, and, I am sure, so will all others who read this book whether they do so for practical or theoretical reasons." From the Foreword by Professor Joshua Fishman Covering the many different kinds of family bilingualism that can arise in modern society and written with the needs of parents in mind, this best selling title is essential reading for healthcare personnel, pre-infant school teachers and students of education psychology and linguistics.

Contents: Foreword (by Prof. Joshua A. Fishman); 1. Introduction; 2. Immigrant Parents; 3. The Effects of Bilingualism on the Child's Development; 4. Raising Children Bilingually in the Family: Some Research Findings with Regard to the Minority Language; 5. How Children Learn Language; 6. Learning Two Languages: Simultaneous and Successive Bilingualism; 7. Language Strategies in the Family; 8. Family Goals with Regard to Degree of Bilingualism; 9. Practical Suggestions for Raising Children Bilingually Inside the Home; 10. Practical Suggestions for Raising Children Bilingually Outside the Home; 11. Case Studies: Meet Several Bilingual Families.

Paperback 0-905028-70-8 £6.95 (US\$15.00)

Hardback $0-905028-71-6 \quad £ 20.00$ (US $\$ 42.00$ )

1987 MM29 168 pages

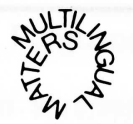
MULTILINGUAL MATTERS LTD
Bank House, 8a Hill Road, Clevedon Avon, England, BS21 7HH

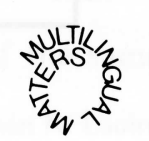




\section{THE BILINGUAL FAMILY NEWSLETTER}

Editor: George Saunders

This exciting quarterly publication is designed to help all those families who, for various reasons, are in a situation where they can give their children (and themselves) the advantages of being bi- or (multi) lingual. The Newsletter publishes short, informative articles on current thoughts on language learning, bilingualism, biculturalism, mother tongue, schools, etc. It also publishes descriptions of how particular families have managed in their particular situations, problems encountered and how these were overcome. The Bilingual Family Newsletter also acts as a means of communication between similar families by providing answers to readers' queries not only from experts but also from other readers.

If you are in a potentially bilingual situation, see how The Bilingual Family Newsletter can help you by sending for a free sample copy or, better still, take out a subscription now.

\section{Recent and forthcoming articles:}

- Sign Language: "Poetry in Motion"

- Flourishing Even with Four Languages

- Language Development of a German-English Bilingual

- Good Advice

- Parents of Bilingual Families Meet

Subscription price includes delivery by air. Four issues per year.

Subscriptions: UK $£ 4.10$ or Overseas $£ 4.50$ (US\$10.00)

Payment may be made by

ACCESS/MASTERCARD/EUROCARD/AMERICAN EXPRESS/DINER'S CARD

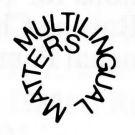

MULTILINGUAL MATTERS LTD Bank House, 8a Hill Rd, Clevedon, Avon, England, BS21 7HH 